\title{
Long term audiometric outcomes following stapedectomy with the shape memory nitinol stapes prosthesis
}

\author{
1,2Rebecca L Heywood, ${ }^{3}$ Mark E Quick, 1,2Marcus D Atlas \\ ${ }^{1}$ Ear Science Institute Australia, ${ }^{2}$ Ear Sciences Centre, The University of Western Australia and ${ }^{3}$ Department of \\ Otolaryngology-Head \& Neck Surgery, Sir Charles Gairdner Hospital, Perth, WA, Australia
}

Introduction: Self-crimping pistons were introduced to remove the manual component of the crimping process during stapedectomy. Stable early and intermediate term hearing results equivalent to or better than those achieved using conventional prostheses have been demonstrated using a selfcrimping shape memory nitinol prosthesis. The objective of this study was to assess long term hearing outcomes and their stability following stapedectomy using a self-crimping shape memory prosthesis. The results were compared to those of a group of patients who received a conventional, manually crimped prosthesis.

Methods: Retrospective case note review was performed of all patients who underwent stapedectomy for otosclerosis between July 2001 and November 2008. Patients were included if they had a minimum dataset of preoperative, early postoperative $(\leq 2$ years) and late postoperative ( $\geq 6$ years) audiometry. Fifty six patients who received a SMart prosthesis (Olympus America Inc, Center Valley, PA, USA) are compared to 27 patients who received a conventional, manually crimped titanium prosthesis.

Results: Changes in audiometric parameters with time are shown in Tables 1 and 2. AC, BC and high tone $B C$ all deteriorated. The small increase in $A B G$ was not found to be statistically significant in either group (nitinol: $P=0.93$; titanium: $P=0.53$ ). There was a greater rate of deterioration in $B C$ in the titanium than the nitinol group $(P=0.037)$. Ninety-six percent of patients with a nitinol prosthesis achieved an $A B G \leq 20 \mathrm{~dB}$ at early follow up and this was maintained (96\%) in the long term, whereas the proportion of patients achieving this $A B G$ in the titanium group fell from $92 \%$ at early follow up to $86 \%$ in the long term. The rate of revision surgery was $3 \%(1 / 29)$ in the titanium and $5 \%(3 / 60)$ in the nitinol group. The rate of revision surgery in the nitinol group after one year post surgery was negligible.

Table 2: Change in audiometric values over the course of long-term follow up (early follow-up against late follow-up)

\begin{tabular}{|r|r|r|r|r|r|r|}
\hline & \multicolumn{3}{|c|}{ Nitinol group (n = 56) } & \multicolumn{3}{c|}{ Titanium group (n = 27) } \\
\hline & Mean $\Delta$ & $\mathrm{P}^{*}$ & $95 \% \mathrm{Cl}$ & Mean $\Delta$ & $\mathrm{P}^{*}$ & $95 \% \mathrm{Cl}$ \\
\hline $\mathrm{AC}$ & 4.9 & 0.0001 & $(2.5,7.2)$ & 8.9 & 0.013 & $(2.0,15.8)$ \\
\hline BC & 4.8 & $<0.0001$ & $(2.8,6.8)$ & 7.3 & $<0.0001$ & $(4.1,10.4)$ \\
\hline $\begin{array}{r}\text { High } \\
\text { tone } \\
\text { BC }\end{array}$ & 4.5 & $<0.0001$ & $(2.4,6.5)$ & 5.9 & 0.001 & $(2.5,9.2)$ \\
\hline ABG & 0.1 & 0.93 & $(-1.4,1.5)$ & 1.7 & 0.53 & $(-3.7,7.0)$ \\
\hline \multicolumn{4}{|c|}{} & & \multicolumn{4}{c|}{ Cl: Confidence Interval } \\
\hline
\end{tabular}

Mean $\Delta$ : Refers to the mean of the difference between late follow-up and early follow-up

*: P-values were derived from the paired t-tests
Discussion: In the titanium group there was a gradual, independent increase in each of the $B C$, high tone $B C$ and $A B G$. In the nitinol group the deterioration in $A C, B C$ and high tone $B C$ are almost identical, suggesting that the deterioration in hearing over time is almost entirely a deterioration of the high frequency sensorineural hearing. The rate of deterioration in high tone $\mathrm{BC}$ was very similar in both groups over the course of long term follow up.

Conclusions: The excellent closure of the ABG achieved at early follow up remains remarkably stable up to 12 years. There is no evidence that circumferential firm fixation of the hook around the LPI has a detrimental effect in the long term and in fact the rate of revision surgery after one year post surgery is negligible.

Table 1: Early and late audiometric outcomes for titanium and nitinol groups

\begin{tabular}{|c|c|c|c|c|c|c|}
\hline & \multicolumn{3}{|c|}{ Nitinol $(n=56)$} & \multicolumn{3}{|c|}{ Titanium $(n=27)$} \\
\hline & Mean & SD & Range & Mean & SD & Range \\
\hline \multicolumn{7}{|l|}{$A C$} \\
\hline Preoperative & 59.1 & 18.6 & $\begin{array}{c}31.3 \text { to } \\
106.3\end{array}$ & 51.5 & 14.8 & $\begin{array}{c}33.8 \text { to } \\
87.5\end{array}$ \\
\hline Early post op & 34.2 & 13.8 & $\begin{array}{c}11.3 \text { to } \\
78.8 \\
\end{array}$ & 29.0 & 12.2 & $\begin{array}{c}11.3 \text { to } \\
58.8\end{array}$ \\
\hline Late post op & 39.0 & 15.5 & $\begin{array}{c}15.0 \text { to } \\
76.3 \\
\end{array}$ & 37.9 & 21.3 & $\begin{array}{c}17.5 \text { to } \\
111.3 \\
\end{array}$ \\
\hline \multicolumn{7}{|l|}{$A B G$} \\
\hline Preoperative & 29.5 & 9.6 & $\begin{array}{c}13.8 \text { to } \\
56.3\end{array}$ & 30.1 & 11.8 & $\begin{array}{c}10.0 \text { to } \\
51.3\end{array}$ \\
\hline Early post op & 9.7 & 5.2 & 0 to 28.8 & 11.0 & 7.7 & 2.5 to 42.5 \\
\hline Late post op & 9.8 & 6.1 & $\begin{array}{c}1.3 \text { to } \\
27.5 \\
\end{array}$ & 12.6 & 11.1 & 1.3 to 45.0 \\
\hline \multicolumn{7}{|l|}{ ABG Closure } \\
\hline Preoperative & $\mathrm{NA}$ & $\mathrm{NA}$ & $\mathrm{NA}$ & $\mathrm{NA}$ & NA & NA \\
\hline Early post op & 19.8 & 9.7 & $\begin{array}{c}-2.5 \text { to } \\
43.8\end{array}$ & 19.2 & 12.4 & -5.0 to 41.3 \\
\hline Late post op & 19.8 & 10.2 & $\begin{array}{c}-2.5 \text { to } \\
42.5\end{array}$ & 17.5 & 17.0 & $\begin{array}{c}-33.8 \text { to } \\
41.3\end{array}$ \\
\hline \multicolumn{7}{|l|}{$\begin{array}{l}\text { Change in } \\
\text { high tone } B C \\
\text { level }\end{array}$} \\
\hline Preoperative & NA & $\mathrm{NA}$ & $\mathrm{NA}$ & $\mathrm{NA}$ & $\mathrm{NA}$ & NA \\
\hline Early post op & 4.2 & 6.8 & $\begin{array}{c}-10.0 \text { to } \\
23.3\end{array}$ & 2.1 & 7.2 & $\begin{array}{c}-8.33 \text { to } \\
18.3\end{array}$ \\
\hline Late post op & -0.3 & 9.3 & $\begin{array}{c}-21.7 \text { to } \\
18.3\end{array}$ & -3.8 & 10.6 & $\begin{array}{c}-33.3 \text { to } \\
15.0\end{array}$ \\
\hline \multicolumn{7}{|l|}{$\mathrm{BC}$} \\
\hline Preoperative & 29.6 & 13.3 & $\begin{array}{l}6.3 \text { to } \\
62.5\end{array}$ & 21.3 & 7.2 & $\begin{array}{c}10.0 \text { to } \\
36.3\end{array}$ \\
\hline Early post op & 24.5 & 13.5 & $\begin{array}{l}6.3 \text { to } \\
66.3\end{array}$ & 18.0 & 8.8 & 5.0 to 40.0 \\
\hline Late post op & 29.3 & 14.8 & $\begin{array}{l}8.8 \text { to } \\
62.5\end{array}$ & 25.3 & 14.0 & 9.3 to 66.3 \\
\hline
\end{tabular}

NA: Not applicable

$A C, A B G, B C(0.5,1,2,3 \mathrm{kHz})$; high tone $B C$ level $(1,2,4 \mathrm{kHz})$

Contact: rebecca_heywood@yahoo.com 